\title{
NARCISSISM IN PAULA HAWKINS' NOVEL THE GIRL ON THE TRAIN
}

\author{
Riska Rahayu Roisiah, Pramudana Ihsan, Wijayadi \\ Universitas Muhammadiyah Surabaya, Surabaya, Indonesia \\ E-mail: Riskamatoh@gmail.com
}

Received: 2021-05-25

Accepted: 2021-06-03

\begin{abstract}
Narcissism is one of the most common diseases in psychology, but its concern is the least. Therefore, this research was focused on narcissism disorder of one of the main characters named Megan Hipwell in the novel The Girl on the Train by Paula Hawkin. The analysis was done by applying psychoanalytic theory, in narcissism, which is the most common mental disorder among the members of a society. The method of research was qualitative, which required an in-depth analysis of the literary works used by the writers of this research according to the selected theories. The analysis was aimed to find illustrations and evidence of the main character in the novel The Girl on the Train to illustrate narcissism disorder. In this research, it was found that the main character suffered from narcissistic disorder, such as big ego, over-self confidence, exploitation of Interpersonal relationships, arrogance, and deficient social conscience. The triggers were rationalization and projection.
\end{abstract}

Keywords: Narcissism, Personality Disorder, Defense Mechanism

\section{Introduction}

Many personality problems arise at the present time. Nearly 1 billion people live with mental disorders, and one person dies every 40 seconds due to suicide. It reminds us of the importance of increased attention to neglected mental health. Especially during the Covid 19 pandemic, almost all age groups in various countries are a force to undergo new habits that can be bad for mental health. Humans do have defence mechanisms that will naturally help them deal with things that each individual cannot accept (Ihsan \& Tanaya, 2019). Like antibodies, these defence mechanisms have limitations, so humans cannot rely on them for a long time. People who have suffered long-term abuse are more likely to be diagnosed with certain personality disorders (Kirsten, 2012). Multiple tests (such as blood tests) can identify physical diseases such as heart disease and diabetes. However, considering the personality disorder, more energy is needed to focus on everyone (Tambunan, 2018). By the psychology of literature, the reader would get knowledge about psychology by reading a literary work, in this case, a novel. One of the famous psychological novels in the 21st- century is The Girl on the Train.

The researchers choose The Girl on The Train, a novel written by Paula Hawkins in 2015, because it tells that exploiting psychological power is always fascinating. The novel covers unconscious mental conditions and discusses the reality that hides behind one's fantasies on love and ownership and this study aims to analyze narcissistic disorder of the main character, Megan Hipwell. 
Paula Hawkin as the author of the novel The Girl On The Train, is well-known as the author of the Mystery and Thriller category at the Goodreads Choice Award in 2015. Besides, Paula is also a freelancer in several publications and wrote a financial advice book for women entitled Money Goodness. After her first novel, The Girl On The Train, she also wrote another novel, Into The Water, released in 2017. Hawkin's novels have unique characteristics; most stories have exciting plots and complicated questions that make the audience curious about the story and wait for the story's end. In addition, all her literary works are fascinating to analyze.

Megan Hipwell has an exciting personality that needs to be analyzed. At first glance, Megan looks like a happy wife to have a loyal husband. She is an interesting figure filled with life fantasies that can never be satisfied, and she is also an art gallery artist in a small town. Megan is accustomed to seeking solace elsewhere to fulfil her desires that her husband could not give her. She has drugged Scott during their marriage, a compulsive liar; she has an affair with another man, and she always tries to have an affair with her therapist too. In her mind there is always a thought of pleasure. The character perfectly shows the social behavior disorder of narcissism.

Matters on personality disorders have become more widespread, people are becoming more and more anxious about these mental problems. People begin to randomly guess and diagnose who has this disease or what disease they might have. Narcissism is a psychological disorder.

\section{Literature Review}

\subsection{Personality Disorder}

Personality is defined as a collection of behavioural, cognitive, and emotional patterns (developed by biological and environmental factors). Although there is no universally accepted definition of personality, most theories focus on motivation and psychological interaction with the human environment. At the same time, personality disorder refers to people with mental problems or people who behave abnormally. Many things can cause personality disorders; from the environment or genetics (Kjennerud, 2014). In other words, genes and the environment are both crucial factors in the development of human thinking.

Feist and Feist (2008) believe that those psychologically disturbed people are incapable of love and have failed to establish a union with others. Psychologically impaired people refer to people with personality disorders. People with mental illness do not receive enough love and cannot socialize themselves with other people. Lenzenweger and Clark say in Feist and Feist (2008), "When they encounter situations in which their typical behaviour patterns do not work, they are likely to intensify their inappropriate ways of coping, their emotional controls may break down, and unresolved conflicts tend to reemerge". Like other humans with typical personalities, people with personality disorders think they are normal. However, when they feel their situation is overwhelmed, they will do their best to solve their problems. People with personality disorders usually live in harsh environments that are mentally unacceptable.

Nonetheless, the environment is not a single factor; it could be started from poor treatment of genetics and the environment, making the people's mentality better. If something disturbs his inner peace, he usually uses defence mechanisms. But in the long run, these defence mechanisms will be ineffective, and personality disorders will develop in their place. 


\subsubsection{Narcissism}

In his psychoanalytic theory, Freud explains that narcissism is a theory of libido or sexual needs; libido is directed towards both oneself (ego-libido) and others (object-libido) (Adams, 2014). When in love, individuals prioritize others they love, but narcissists prioritize themselves. In short, narcissism is when the ego is much more deeply involved than usual. In the social psychology view of personality, narcissism uses social relationships to regulate self-concept and self-esteem. Narcissists do not pay attention to interpersonal intimacy, warmth, or other positive long-term relationships. They are still very good at building relationships and use these relationships to show popularity, success, and high status in the short term (Campbell et al., 2010). From a clinical and social personality point of view, narcissism includes aspects of maintaining self-esteem or self-improvement. They try to achieve personal goals without wanting to empathize with the interests of others around them. It can be seen from the selfish attitude or the tendency to use anything to enhance his persona. Narcissists tend to blame other situations or people if what they want is not achieved (Campbell et al., 2010).

Narcissism is a personality characterized by excessive fantasies or behavior towards power, beauty, success, or ideal love, a great need to be admired by others, and a lack of empathy based on Diagnosis and Statistical Manual of Mental Disorder IV-R. The psychological approach reveals the novel characters' pattern to determine the novel's narcissism.

Five criteria of narcissistic personality disorder:

1. Inflated self-image (e.g., displays cocky self-assurance and exaggerates achievements; seen by others as self-centered, haughty, and arrogant).

2. Interpersonal exploitativeness (e.g., used to enhance self and indulge desires)

3. Cognitive expansiveness (e.g., used to exhibit immature fantasies and redeem selfillusions

4. Insouciant temperament (e.g., manifesting a general air of nonchalance and imperturbability).

5. Deficient social conscience (e.g., disregarding conventional rules of shared social living, viewing them as naïve or inapplicable to self; revealing a careless disregard for personal integrity and an indifference to the rights of others) (Weiner \& Craighead, 2010)

In social conditions, narcissism can create a need for power over others. This situation is forming because the narcissistic individual needs to be appreciated, recognized, praised, and seen as achieving. This need reflects the narcissistic individual's dependence on external sources of gratification but rejects those external sources' consequences or responsibility (Campbell et al., 2010). Even so, society generally rejects individuals like this. There are many reasons. The narcissistic individual exaggerates his accomplishments, only wants to befriend those who admire him, resists criticism, is arrogant, aggressive, self-promoting, and disliked. There are four types of narcissism: individuals who love themselves, individuals who love themselves in the past, individuals who love themselves in the future, and individuals who love individuals who used to be part of themselves (Adams, 2014). Most narcissists understood today are the self-loving type of all time. Even so, individuals who like themselves in the past - which means they don't love themselves now - and individuals who have huge aspirations about themselves in the future classified as narcissistic individuals.

The narcissist may look solid, brimming with force and predominant. However, these people try to reduce their endurance by showing others the reality they cannot survive. 
Even if they lie when necessary, so that individuals applaud for them, in this way, they gather the energy for survival, and ultimately, they believe in their mistakes. Narcissism's role is practically something very similar to the vast majority of defence mechanism's roles: securing and serving the delicate self. It can be proved that they are worthy of attention, thus linking things they have or recognized by society. Narcissism has no specific knowledge of this problem; however, many young people and people in the mid-1920s are most prone to this problem. In any case, middle-age is when narcissism worsens. (Adams, 2014).

\subsection{Defence Mechanism}

We realize that humans have an instinct to always live like animals, but not only that, humans have something not only always alive, morals, loyalty, etc. Humans can consider morals and aesthetics, and it can be that only humans who enjoy moral and political status and dignity have rights (Ihsan \& Tanaya, 2019). Humans somehow want morality, evaluation, etc., which are established by the citizens and make all the community veins agree with the truth and judgment. Citizens determine things based on human attitudes, which they impose as good attitudes and standardize human morality. However, different people are ignored by them. Those who are different do look at as bad people who are treated poorly by those around them. Therefore, humans have a defence mechanism to be free from mental destruction. It is what the writers intend to discuss in this research.

The defence mechanism is an instrument made by the mind of the person that aims to make people feel comfortable in their environment, and the central defence is used to protect humans by keeping up unsatisfactory driving forces, emotions on the primary side of the human mind's consciousness (Cramer, 2000). Thus, the defence mechanism serves to control anxiety. Anxiety on a large scale can cause problems for these individuals, such as depression, and what is even worse is personality disorders (Ihsan \& Tanaya, 2019). People have a great deal of anxiety, like uneasiness about their future, being separated from everyone else, being left, and tension for a vast scope can inconveniences the individual, like discouragement. The more terrible is a behavioral condition. Indeed, this defence mechanism either avoids or controls the human mind from being destroyed by all these anxieties.

Defence mechanism has several forms: repression, reaction formation, displacement, fixation, regression, projection, rejection, and sublimation (Cramer, 2000).

Every individual uses Defense mechanism instruments that are unknowingly performed by numerous individuals when they feel insecure about something. Individuals can't deliberately pick which Defense mechanism they will utilize or which Defense mechanism fits them better. The oblivious human perspective will figure out which Defense mechanism instrument will do with the person's character and what Defense mechanism the people need during that time. Researchers only took three mechanisms for this study of the ten mechanisms described by Freud. The defence mechanisms for the ego are as follows Projection and Rationalization.

1. Projection

Projection is a form of self-defense by dealing with disturbing anxiety by distorting the facts as if the guilty party is someone else, not himself. On the other hand, Projection is a defence mechanism that emerges when we share our weaknesses, problems, and mistakes with others (Cramer, 2000). 
2. Rationalization.

A rationalization is a form of self-defence by making excuses to manipulate facts so that the actions taken make sense and can be accepted. We justify a thought or threatening action by persuading ourselves that there is a rational explanation for the view or activity. A psychoanalytic defence mechanism occurs when the ego does not accept the real motive of individuals' behaviour and replaces it with a hidden reason. Here the action is perceived, but the explanation that caused it is not. Behaviour reinterprets to look reasonable and acceptable (Weiner \& Craighead, 2010).

\section{Research Method}

Megan Hipwells' The Girl on the Train is the object of the study. This analysis is done by applying psychoanalytic theory, especially in narcissism, which is the most common mental disorder in society, and people's consciousness is now lacking. The method is qualitative, requiring an in-depth analysis of the literary works of this study according to the selected theories. A descriptive qualitative research design has been carried out since the data are in words, phrases, sentences, and utterances. The data are of primary and secondary ones. The preliminary data are taken from the novel, and the auxiliary information is taken from other sources. The data for this study are collected by reading, identifying, interpreting, and counting citations in the novel. In addition, the data are analyzed based on the theory of narcissistic disorder.

\section{Results and Discussion}

Personality disorders are not another new issue in society. Regarding personality disorders, many people, for the most part, consider it a maniac or an odd individual. Indeed, individuals with Personality disorders do not generally appear to have issues with their minds. An individual with an ordinary appearance does not preclude that person is diagnosed with a psychological disorder. Therefore, it is harder to perceive mental illness than physical illness. Likewise, Personality Disorders are not identified with sociopaths, manslaughters, double personality, and so on. The minor simple things like over-self confidence can show a personality disorder with a specific classification, and individuals called that narcissism disorder. The following are the characteristics of the narcissistic disorder in the character Megan Hipwell.

\subsection{Over self- confident}

An individual has a high admiration for himself; he can be considered to have a narcissistic disorder. (Campbell et al., 2010) states that "Narcissism is associated with over self-confidence......" The following citations represent her over self-confidence

I find myself standing in front of my wardrobe, staring for the hundredth time at a rack of pretty clothes, the perfect wardrobe for a manager of a small but cutting-edge art gallery. Nothing in it says 'nanny' (Hawkin, 2015: 24).

People who have narcissistic personality disorder feel that their social status is the highest. They feel special and always want to be privileged by others. The cause of a symptom is the level of confidence that is too high to maintain their existence. According to him, the clothes are not suitable for babysitters. Such evidence proves that Megan feels she is unique because she has a higher status than the nanny in dressing. It shows that she takes 
care of her appearance, makes herself look physically perfect, and becomes an outstanding individual compared to others. They further explain that individuals who like to preen, dress up, and want to admire themselves could be said to be narcissistic. The fact that Megan likes preening is shown in the following dialogue "I long for my days at the gallery, prettied up, hair done......" (Hawkin, 2015: 25). Narcissism is self-love, excessive concern for oneself, characterized by very extreme respect for oneself.

\subsection{Exploitation of the Interpersonal Relationships}

In narcissistic behaviour, interpersonal relationships mean exploiting others to achieve their own goals-women who are busy directing their narcissistic attitude to achieve the desired goal. The relation is considered as satisfying herself.

"......jumble up all the men, the lovers, and the exes, but I tell myself that's OK because it doesn't matter who they are. it matters how they make me fell......why can't they give it to me? " (Hawkin, 2015: 74).

\section{and}

"I was with a man who excited me, who adored me......I didn't need it to endure, or sustain. I just needed it for right then" (Hawkin, 2015: 221).

She is an interesting figure filled with life fantasies that can never be satisfied. She is accustomed to seeking solace elsewhere to fulfil desires that her husband could not accomplish. She is just thinking about the pleasure. In normal conditions, almost all women choose to be faithful. Megan has a lot of faith in her husband's loyalty to their marriage. However, narcissistic individuals fail to build specific interpersonal relationships such as dating because they negatively impact weak commitment, infidelity, and high and unlimited sociosexuality (Campbell et al., 2010). Megan has indicated narcissism disorder seen through her affairs with several men in her life.

".... I saw him, and I wanted him, and I thought, why not? I don't see why I should have to restrict myself, lots of people don't. men don't." (Hawkin, 2015: 61).

Even though Megan knows the man has already had a family, that does not stop her . Megan meets the man at a hotel. She is cautious because she knows if what she does is found out by Scott, bad things happen to her. It would be a disaster for the guy to cheat on. Significantly narcissistic is associated with dominating, vengeful behaviour. (Campbell, 2010). Whereas in the social psychology view of personality, narcissism uses social relationships to regulate self-esteem and self-concept. Narcissists do not focus on interpersonal intimacy, warmth, or other positive long-term relationships .... (Campbell et al., 2010)

\subsection{Big Ego}

Eugene states that "Anything other than the ego is narcissism...". When one thinks that nothing is more important than oneself, a big ego can lead to a narcissistic disorder: the bigger ego, the more difficult it is to become selfless. Most narcissists are people with big egos who try to impose their will on others. They usually do something necessary to meet their needs, such as feeling comfortable, happy, or anything that benefits them. The big ego of Megan seen on page 216

" I'm going to have to swallow my pride and my shame and go to him. He's going to have to listen. I'll make him" (Hawkin, 2015: 216). 
It means what Megan does to Kamal is one of the characteristics of a narcissist. Megan sees herself as a unique individual. She believes that her affairs are always more important than the other's affairs. Her attitude has a centered attitude towards her that ignores the people who are in the vicinity. It is caused by the perception from within themselves higher than others. She also hopes to be prioritized in terms of excellent and special treatment or unreasonable, meaning priority arises. Their demand are to be fulfilled automatically, and that is suitable for their expectations. Megan often feels she has the right to get good things that have advantages for her.

\subsection{Being Arrogant Women}

Megan is also an arrogant woman. The attitude is shown by Megan as she wants others to understand her suffering for Scott's behaviour. Still, she also wants to be seen as acceptable in her absence. This attitude gives rise to the thought that Megan feels excellent and capable even without Scott.

"I can live without him, I can do without him just fine-but don't like to lose.

It's not like me. None of this is like me. I don't get rejected. I'm the one who walks away" (Hawkin, 2015: 174).

Megan's attitude in the above quote shows that she can go through life without Scott, which indirectly indicates she displays cocky self-assurance, making an Inflated self-image. According to Concini (Weiner \& Craighead, 2010), inflated self-image is one of the five narcissistic characteristics. The narcissistic tendency will lead her to an extreme ego or me. In that condition, women are not easily conquered, defending their dignity, physically and psychologically. It is due to a stable level of consciousness in the appreciation of his weaknesses.

\subsection{Deficient Social Conscience}

Corsini mentions five criteria of narcissistic personality disorder, one of which is the deficient social conscience. It is found in the following excerpt.

"I didn't want him to leave his wife, just wanted him to want to leave her. to want me that much "(Hawkin, 2015).

Based on the data above quote, Megan cannot understand the feelings of others, especially understanding the sentiments of Anna, the wife of Tom. Narcissistic women have a centered attitude ignoring the people who are in the vicinity. Excessive confidence in the ability of self makes women feel narcissistic andhampered for sensitivity toward others. Megan wants Tom to leave his wife. Even though Megan knows Tom has already a child with Anna, that does not stop her from expecting Tom. Megan shows Deficient social conscience, disregards conventional rules of shared social living, revealing an indifference to the rights of others.

\subsection{Defence Mechanism}

Megan displays the typical narcissistic trait of repressing unwanted thoughts and memories. Narcissists have a variety of defence mechanisms at their disposal. There are two aspects in Defence Mechanism: projection and rationalization. 


\section{Projection}

Megan's first projection is made towards Scott. Megan says that Scott is so tired all the time. She is not interested anymore. He cannot provide what she needs. Everything she thinks only about the baby (364-365). He is no longer available to him. That fact is the reason why she starts to find out another man who is known to him. It is Tom. Projections occur to protect the ego from guilt or fear/worry (Cramer, 2000). By projecting Scott, she tries to defend herself from Scott's judgment for her affair.

\section{Rationalization}

The rationalization is used by Megan when neurotic anxiety attacks her when Mac has realized that she is the person who kills Libby. Therefore, his rationalization is used by making several reasons why she kills her baby. She reveals that she does not mean this. A defence mechanism occurs when the ego does not accept the real motive of individuals' behaviour and replaces it with a hidden reason (Cramer, 2000). She hopes that Mac and Kamal do not blame her for this by doing a rationalization defence mechanism. Megan's thoughts indicate that she uses primary narcissistic defence mechanisms to cope with unwanted thoughts and memories.

\section{Conclusion}

Narcissism is a personality disorder caused by past mental abuse, and narcissists do their best to prove themselves superior. The narcissistic in the novel Girl On The Train can found in Megan Hipwell, an art gallery artist who ironically has a personality disorder. Her behaviours, such as her big ego, over-self confidence, Exploitation of Interpersonal Relationships, being arrogant woman, and deficient social conscience, clarify that Megan is a narcissist. Narcissism in the novel is also caused by the harassment of the main character by the environment. In real life, narcissists believe to be selfish, meaning they only care for them and put everyone after them. But it is these people who feel the most insecure about their existence. That is why these people try to protect their existence by rationalization and projection.

\section{References}

Adams, M. (2014). Narcissism, Overview. October, 6-9. https://www.researchgate.net/publication/285604374_Narcissistic_for_the_People_ Narcissists_and_Nonnarcissists_Disagree_about_How_to_Make_a_Good_Impression.

Campbell, W. K., Miller, J. D., \& Widiger, T. A. (2010). Narcissistic Personality Disorder and the DSM-V. Journal of Abnormal Psychology, 119(4), 640-649. https://doi.org/10.1037/a0019529

Cramer, P. (2000). Defense mechanisms in Psychology Today: Further Processes for adaptation. American Psychologist, 55(6), 637-646. https://doi.org/10.1037/0003066X.55.6.637

Feist and Feist. (2008). Theories of Personality, Seventh Edition. New York: McGraw-Hill. (seventh)

Hawkin, P. (2015). The Girl On The Train.. NJ: Riverhead Books; Media Tie

Ihsan, P., \& Tanaya, O. R. D. (2019). Narcissism Analysis of Rupert in Paul Howard Surridge's All in the Mind. Humanities and Social Sciences Reviews, 7(3), 115-120. https://doi.org/10.18510/hssr.2019.7318 
Kirsten, Weir. (2012). How Much of mental illness can the Biology of the Brain Explain? The Roots of Mental Illness. Monitor on Psychology.

Kjennerud, T. R. (2014). Genetics of Personality Disorders. Clinics in Laboratory Medicine, 30(4), 893-910. https://doi.org/10.1016/j.cll.2010.07.011

Tambunan, H. (2018). Impact of Heuristic Strategy on Students' Mathematics Ability in High Order Thinking. 13(3), 321-328. https://doi.org/10.12973/iejme/3928

Weiner, Irving B., \& Craighead, W. Edward. (2010). The Corsini Encyclopedia of Psychology. The Corsini Encyclopedia of Psychology. John Wiley \& Sons, Inc. https://doi.org/10.1002/9780470479216 